\title{
Peroxisome Proliferator-Activated Receptor $\gamma$ Agonists Enhance Lung Maturation in a Neonatal Rat Model
}

\author{
YING WANG, JAMIE SANTOS, REIKO SAKURAI, EUGENE SHIN, LAURA CERNY, JOHN S. TORDAY, AND VIRENDER K. REHAN
}

Department of Pediatrics [Y.W., J.S., R.S., E.S., L.C., J.S.T., V.K.R.], Department of Obstetrics and Gynecology [J.S.T.], David Geffen

School of Medicine at University of California, Los Angeles, Torrance, California 90502

\begin{abstract}
The nuclear transcription factor peroxisome proliferator-activated receptor (PPAR) $\gamma$ plays a central role in normal lung development. However, the effects of modulating PPAR $\gamma$ expression by exogenously administered PPAR $\gamma$ agonists on lung development and basic blood biochemical and metabolic profiles in a developing animal are not known. To determine these effects, newborn SpragueDawley rat pups were administered either diluent or rosiglitazone (RGZ), a potent PPAR $\gamma$ agonist, for either 1 or $7 \mathrm{~d}$. Then the pups were killed and the lungs were examined for specific markers of alveolar epithelial, mesenchymal, and vascular maturation, and lung morphometry. The effect of RGZ on a limited number of blood biochemical and metabolic parameters was also determined. Overall, systemically administered RGZ significantly enhanced lung maturation without affecting serum electrolytes, blood glucose, blood gases, plasma cholesterol, triglycerides, and serum cardiac troponin levels. The lung maturation effect of PPAR $\gamma$ agonists was also confirmed by another PPAR $\gamma$ agonist, the naturally occurring PPAR $\gamma$ ligand prostaglandin $\mathrm{J}_{2}$. We conclude that systemically administered RGZ significantly enhances lung maturation without significantly affecting the acute blood biochemical and metabolic profiles, providing rationale for further studying PPAR $\gamma$ agonists for enhancing lung maturation, and for promoting lung injury/repair in neonates. (Pediatr
\end{abstract} Res 65: 150-155, 2009)

$\mathrm{P}$ eroxisome proliferator-activated receptor (PPAR) $\gamma$, a member of the retinoid X-receptor heterodimer family of the retinoid/steroid/thyroid hormone superfamily of ligandactivated nuclear receptors, plays a central role in lipid storage and metabolism in various organs, including the lung $(1,2)$. Recently, it has been demonstrated to play a central role in normal lung development by stimulating the alveolar epithelial-mesenchymal paracrine signaling that is critical for normal lung development $(3,4)$. However, the effect of manipulating PPAR $\gamma$ expression by exogenously administered PPAR $\gamma$ agonists on lung development in a developing animal is not known. This is important because steroid administration, the contemporary standard intervention to enhance fetal lung maturation, has significant limitations. For example, this therapy, is effective in only $50-70 \%$ of infants, is sex-specific, has a delayed onset of action, and with repeated use, it may

Received April 30, 2008; accepted September 12, 2008

Correspondence: Virender K. Rehan, M.D., Department of Pediatrics, Los Angeles Biomedical Research Institute at Harbor UCLA Medical Center, David Geffen School of Medicine at UCLA, 1124 West Carson Street, Torrance, CA 90502; email: vrehan@labiomed.org

This study was supported by grants from the NIH (HL075405 and HL55268) and the TRDRP (14RT-0073 and 15IT-0250). result in significant somatic growth restriction and neurodevelopmental handicaps (5-8). Similarly, all-trans retinoic acid, another agent that is known to promote alveolarization in both neonatal and adult animal models, is also known to exhibit well-documented teratogenic effects, its effects are species specific, and it does not result in improved pulmonary function $(9,10)$. In view of the limited options for agents that can be used to stimulate lung maturation, alternate strategies for accelerating fetal lung maturation that are uniformly effective and safe are needed.

In the present work, using a neonatal rat model for lung development, we sought to examine the effects of the systemically administered PPAR $\gamma$ agonists rosiglitazone (RGZ) and prostaglandin $\mathrm{J}_{2}\left(\mathrm{PGJ}_{2}\right)$ for up to $7 \mathrm{~d}$ on selected markers of lung differentiation, and to determine whether this intervention affects the basic blood biochemical and metabolic profiles of the treated animal. We hypothesized that PPAR $\gamma$ agonists given systemically would enhance lung maturation without significantly altering basic blood biochemical and metabolic profiles. Therefore, following systemic PPAR $\gamma$ agonist administration, lung maturation was assessed by examining the expression of key alveolar epithelial and mesenchymal molecular markers that are the hallmarks of lung maturation in the developing lung, including the expressions of surfactant proteins (SP) B and C, choline incorporation into saturated phosphatidylcholine, triolein uptake by the lung, and by lung morphometry. The effects of systemically administered RGZ on basic blood biochemical and metabolic profiles was assessed by measuring serum electrolytes, blood gases, blood glucose, cardiac troponin, and plasma cholesterol and triglycerides.

\section{METHODS}

Animal protocol. Pathogen-free, timed (time e0 = day of mating), firsttime pregnant Sprague Dawley rats (200-220 g) were obtained from Charles River (Holister, CA) at day 16 of gestation and were allowed to acclimatize in humidity - and temperature-controlled rooms on a 12:12-h-light:dark cycle, and were allowed food and water ad libitum. On d22 of pregnancy, dams were allowed to deliver spontaneously. Newborn pups receiving RGZ were divided into the following six groups-control, RGZ $0.1 \mathrm{mg} / \mathrm{kg}, 0.3$ $\mathrm{mg} / \mathrm{kg}, 1 \mathrm{mg} / \mathrm{kg}, 3 \mathrm{mg} / \mathrm{kg}$, or $8 \mathrm{mg} / \mathrm{kg}$ groups. The diluent (saline) or RGZ (Cayman Chemicals, Ann Arbor, MI) was administered intraperitoneally with

Abbreviations: ADRP, adipocyte differentiation-related protein; ATII, alveolar type 2; PPAR $\gamma$, peroxisome proliferator-activated receptor gamma; $\mathbf{P G J}_{\mathbf{2}}$, prostaglandin $\mathrm{J}_{2} ; \mathbf{P T H r P}$, parathyroid hormone-related protein; RGZ, rosiglitazone; $\mathbf{S P}$, surfactant protein 
a microsyringe in $100 \mu \mathrm{L}$ volumes once daily for either 1 or $7 \mathrm{~d}$. The first dose of RGZ was administered as soon as possible after delivery, and in no case was the interval between the administration of the first dose and killing at $24 \mathrm{~h}$ less than $22 \mathrm{~h}$. To demonstrate that the effects of PPAR $\gamma$ agonists on lung maturation are not RGZ-specific, some animals received the PPAR $\gamma$ agonist $\mathrm{PGJ}_{2}$ at $0.1 \mathrm{mg} / \mathrm{kg}, 0.3 \mathrm{mg} / \mathrm{kg}, 1 \mathrm{mg} / \mathrm{kg}$, or $10 \%$ dimethyl suphoxide (vehicletreated controls) in $100 \mu \mathrm{L}$ volumes administered intraperitoneally once daily for $7 \mathrm{~d}$. At the end of each experimental period, the pups were killed using 0.1 $\mathrm{mL}$ euthasol per pup. The lungs were collected and processed either immediately for $\left[{ }^{3} \mathrm{H}\right]$ choline incorporation and $\left[{ }^{3} \mathrm{H}\right]$ triolein uptake, or flash-frozen for later Western hybridization for the markers of lung maturation. Tissue was also processed for lung morphometry and lamellar body staining as described below. To determine the effects of systemically administered RGZ on PPAR $\gamma$ and its down-stream target adipocyte differentiation-related protein (ADRP), expression in selected extra-pulmonary tissues, peritoneal fat, liver, and kidneys were flash-frozen from the killed animals. Blood was collected by cardiac puncture from each pup and either processed immediately for blood gases, electrolytes, and glucose analysis, or frozen at $-80^{\circ} \mathrm{C}$ for later determination of blood cholesterol, triglyceride, and cardiac troponin levels. A total of 20 pups were used for each condition (2-3/litter). All animal procedures were performed following the guidelines of the $\mathrm{Na}$ tional Institutes of Health for the care and use of laboratory animals, and approved by the Los Angeles Biomedical Research Institute, Animal Care and Use Committee.

Western blot analysis. Western analysis was performed as described previously (11). The specific primary antibodies used included PPAR $\gamma$ (1:2000, Alexis Biochemicals, San Diego, CA), SP-B and SP-C (1:2000 for each, Chemicon, Temecula, CA), cholinephosphate cytidylyltransferase- $\alpha$ (CCT- $\alpha)(1: 2000$, a gift from Dr. Mallampalli, University of Iowa, IA), parathyroid hormone-related protein (PTHrP) receptor $(1: 100$, Upstate, Temecula, CA), ADRP (1:3000, a gift from Dr. Constantine Londos, NIDDK); vascular endothelial growth factor (VEGF), and FLK-1 (1:350 for each, Santa Cruz, Biotechnology, San Diego, CA). The blots were subsequently stripped and reprobed with anti-GAPDH antibody (1:10,000, Chemicon, Temecula, CA), and specific protein values were normalized to GAPDH.

Lung morphology. Rat lung was inflated in situ with $4 \%$ paraformaldehyde in phosphate buffer at a standard inflation pressure of $5 \mathrm{~cm}$ of $\mathrm{H}_{2} \mathrm{O}$, and was fixed as described previously (11). An investigator unaware of the treatment groups performed lung morphometry, which was objectively assessed by determining the radial alveolar count (RAC) and mean linear intercept (MLI) methods on H \& E stained sections. Fifty randomly selected, nonoverlapping fields from sections obtained from 12 blocks from each treatment group were included for measurement. Briefly, radial alveolar counts were performed by identifying respiratory bronchioles, as described by Randell et al. (12). The MLI, which represents the average alveolar diameter, was analyzed with Image-Pro plus image-analysis software (Zeiss, Germany). Slides were examined at 100-fold magnification and at least two sections from each pup were used, and a minimum of six animals from each group were analyzed.

Lamellar body staining. P180 lamellar body protein expression was assessed by immunofluorescence staining. Briefly, $8 \mu \mathrm{m}$ cryosections were incubated with lamellar body MAb (1:500 dilution, COVANCE, Berkeley, $\mathrm{CA})$ at room temperature for $1 \mathrm{~h}$ and then the secondary antibody goat anti-mouse Rhodamine IgG (1:200 dilution, Santa Cruz, CA) was applied to the sections for another $30 \mathrm{~min}$. The sections were washed with PBS and then mounted with Vectashield mounting medium with DAPI for visualization under a fluorescence microscope.

Triglyceride uptake and choline incorporation into saturated phosphotidylcholine assays. Triglyceride uptake and incorporation of [methyl- $\left.{ }^{3} \mathrm{H}\right]-$ choline chloride (NEN Dupont) into saturated phosphatidylcholine in cultured lung explants was determined as described previously (12).

Blood gas, glucose, and serum electrolytes assays. These parameters were assayed, using I-Stat (Abbott Laboratories, Abbott Park, Illinois), cartridge $\mathrm{EC} 8+$, according to the manufacturer's protocol.

Plasma cholesterol and triglyceride determination. These were measured by enzymatic methods, using the RAICHEM kit (Hemagen Diagnostics, San Diego, CA), following the manufacturer's protocol.

Measurement of serum cardiac troponin I levels. Serum cardiac troponin I levels were determined by a rat cardiac Tn-I ELISA kit as per the manufacturer's protocol (Cat. \# 2010-2-HS, Life Diagnostics, West Chester, PA). The detection limit of this assay is $0.156 \mathrm{ng} / \mathrm{mL}$.

Statistical analysis. ANOVA was used to statistically analyze the experimental data. $p \leq 0.05$ was considered to indicate statistically significant differences between the experimental groups.

\section{RESULTS}

Effect of RGZ on alveolar epithelial differentiation. Because pulmonary surfactant is a key marker of lung epithelial differentiation, we examined the effect of RGZ administration on surfactant protein and phospholipid synthesis. Compared with the controls, RGZ administration increased SP-B and SP-C expression on both days 1 and $7\left(^{*} p<0.05\right.$, RGZ versus control; Fig. $1 A$ and $B$ ), with greater effects at 0.3 and $1 \mathrm{mg} / \mathrm{kg}$ for SP-B, and at 1 and $3 \mathrm{mg} / \mathrm{kg}$ for SP-C expression. Similarly, after RGZ administration, the expression of CCT- $\alpha$, the ratelimiting enzyme in surfactant phospholipids synthesis, increased significantly on both days 1 and 7 at all doses of RGZ examined except at the $8 \mathrm{mg} / \mathrm{kg}$ dose $(* p<0.05, \mathrm{RGZ}$ versus control; Fig. 1C). This effect was also mirrored by significantly increased $\left[{ }^{3} \mathrm{H}\right]$ choline incorporation into saturated phosphatidylcholine, a functional marker for surfactant phospholipids synthesis, and hence that of CCT- $\alpha$ enzyme activity $\left({ }^{*} p<0.05\right.$, RGZ versus control; Fig. $\left.1 D\right)$. Increased alveolar epithelial differentiation by RGZ treatment is also reflected by the increased lamellar body staining at both days 1 and 7 , as determined by specific labeling for p180 lamellar body, a specific marker for alveolar epithelial type II cells $(* p<0.05$, RGZ versus control; Fig. 2).
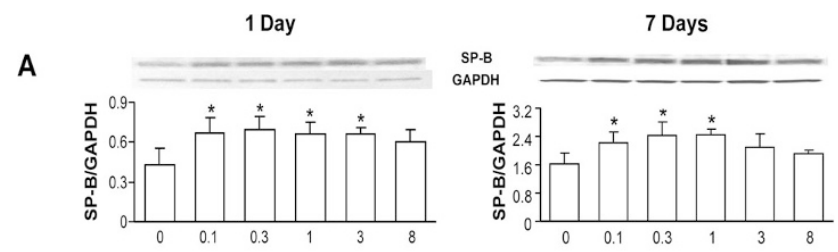

B
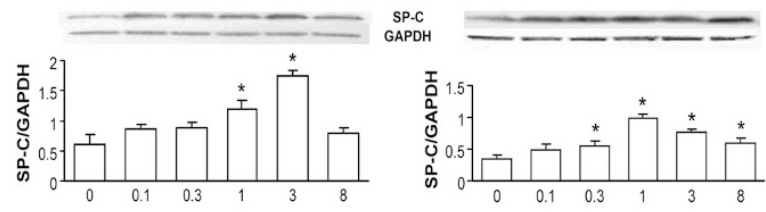

C
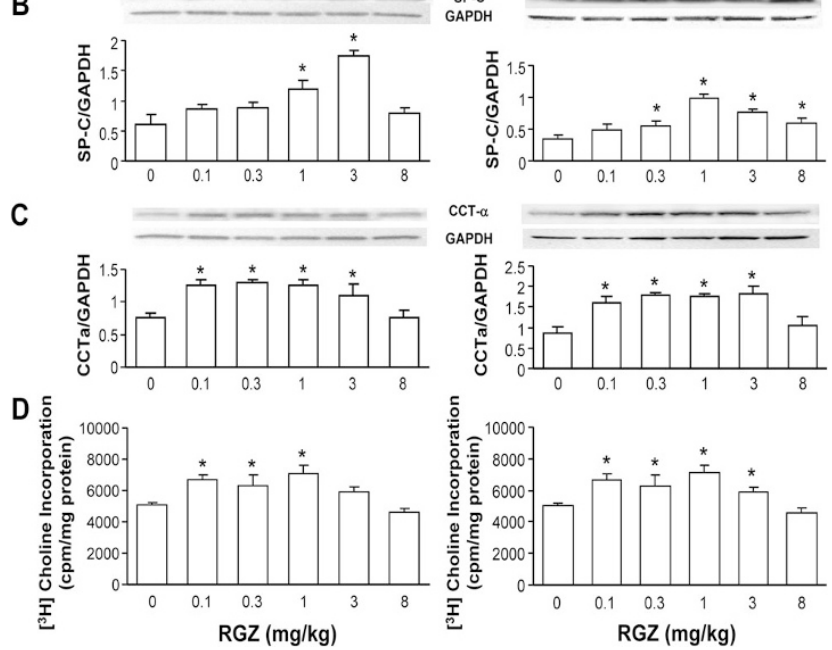

Figure 1. Effect of rosiglitazone on surfactant protein and phospholipid synthesis. The newborn rat pups were administered either diluent or RGZ in graded doses in $100 \mu \mathrm{L}$ volume once daily intraperitoneally for either 1 or $7 \mathrm{~d}$. Compared with the controls, RGZ administration increased surfactant protein B and C expression at both days 1 and 7 (Fig. $1 A$ and $B$ ) with greater effects at 0.3 and 1 $\mathrm{mg} / \mathrm{kg}$ for SP-B, and at 1 and $3 \mathrm{mg} / \mathrm{kg}$ for SP-C expression. Furthermore, compared with the controls, RGZ administration increased cholinephosphate cytidylyltransferase- $\alpha$ expression significantly at both days 1 and 7 at all doses of RGZ examined except at the $8 \mathrm{mg} / \mathrm{kg}$ dose (Fig. 1C). Representative Western blots from the whole lung lysates and the corresponding density histograms are shown $\left(n=5\right.$, mean $\pm \mathrm{SD},{ }^{*} p<0.05, \mathrm{RGZ} v s$. control). RGZ treatment resulted in significantly increased $\left[{ }^{3} \mathrm{H}\right]$ choline incorporation into saturated phosphatidylcholine (Fig. $1 D)\left(n=6\right.$, mean \pm SD, ${ }^{*} p<0.05$, RGZ vs. control). 


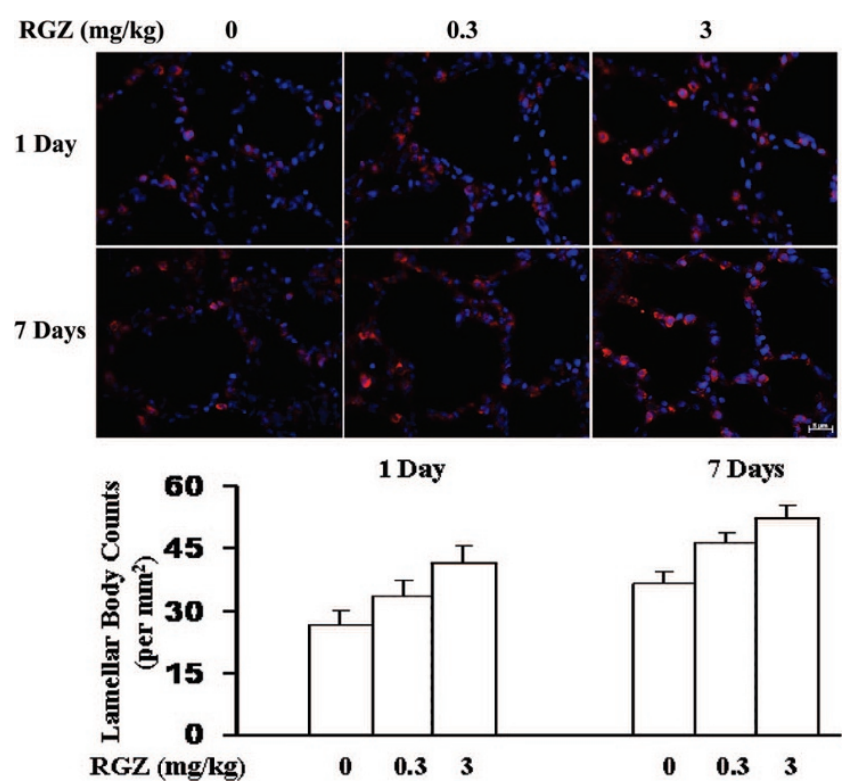

Figure 2. Effect of rosiglitazone on lamellar body number. The newborn rat pups were administered either diluent or RGZ in $100 \mu \mathrm{L}$ volume once daily intraperitoneally for either 1 or $7 \mathrm{~d}$. With RGZ treatment, there was significantly increased lamellar body staining at both days 1 and 7 as determined by specific labeling for the lamellar body marker p180. Representative cryostat sections of fixed lung tissue labeled with p180 lamellar body (red staining) are shown. DAPI was used for counterstaining $\left(n=5\right.$, mean $\pm \mathrm{SD},{ }^{*} p<0.05$ vs. control). Magnification $\times 40$.
A

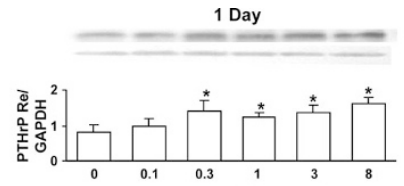

B

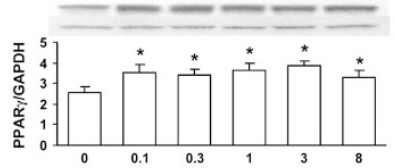

C
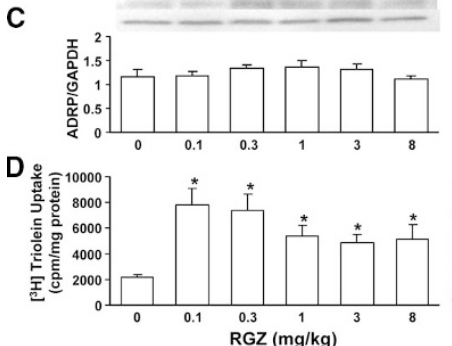
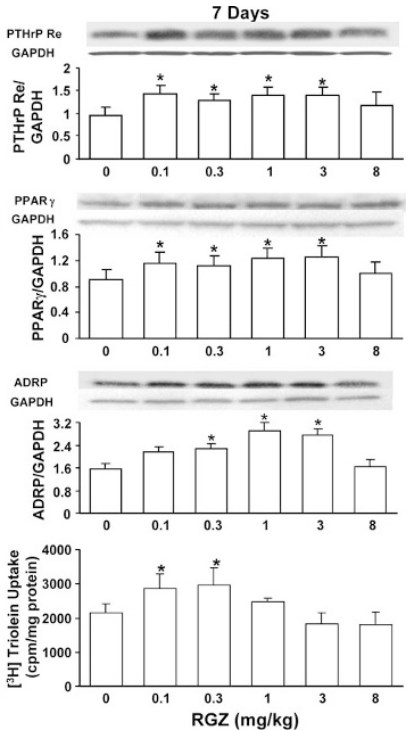

Figure 3. Effect of rosiglitazone on prohomeostatic mesenchymal markers PTHrP receptor, PPAR $\gamma$, and ADRP expression and triolein uptake. The newborn rat pups were administered either diluent or RGZ in graded doses in $100 \mu \mathrm{L}$ volume once daily intraperitoneally for either 1 or $7 \mathrm{~d}$. Compared with controls, with RGZ administration there was an overall significantly increased expression of PTHrP receptor (Fig. 3A), PPAR $\gamma$ (Fig. 3B), and ADRP (Fig. $3 C)$ at both days 1 and 7. Representative Western blots from the whole lung lysates and the corresponding density histograms are shown $(n=5$, mean \pm $\mathrm{SD},{ }^{*} p<0.05, \mathrm{RGZ} v s$. control). Furthermore, RGZ treatment significantly increased triolein uptake at both days 1 and 7 (Fig. 3D, $n=6$, mean $\pm \mathrm{SD}$, $* p<0.05$, RGZ vs. control).

\section{Effect of RGZ on alveolar mesenchymal differentiation.} Because we have previously shown that PTHrP/PPAR $\gamma$ signaling is centrally involved in determining alveolar mesen- chymal differentiation, we next examined the effect of RGZ administration on PTHrP receptor, PPAR $\gamma$, and ADRP expression, key markers of alveolar mesenchymal differentiation. Compared with controls, with RGZ administration there was an overall significantly increased expression of PTHrP receptor (Fig. 3A), PPAR $\gamma$ (Fig. 3B), and ADRP (Fig. 3C) at both days 1 and 7 (*p $<0.05$, RGZ versus control). Similarly, with RGZ treatment, triolein uptake, a functional marker of alveolar mesenchymal differentiation, increased significantly, consistent with the increased PTHrP receptor, PPAR $\gamma$, and ADRP expression at both days 1 and $7\left(^{*} p<0.05\right.$, RGZ versus control; Fig. $3 D$ ).

Effect of RGZ on lung morphometry. Histologic examination of lungs obtained from control and experimental animals showed enhancement of alveolarization in both the 0.3 and 3 $\mathrm{mg} / \mathrm{kg}$ RGZ treatment for $7 \mathrm{~d}$ groups (Fig. $4 A$ ), without any significant changes in alveolarization in the $8 \mathrm{mg} / \mathrm{kg}$ RGZ treatment group (data not shown) [mean alveolar counts; $9.1 \pm 1.2$ versus $10.4 \pm 1$ versus $11.3 \pm 1.1$, control versus $\mathrm{RGZ}$ at $0.3 \mathrm{mg} / \mathrm{kg}$ or $3 \mathrm{mg} / \mathrm{kg}$, respectively, $* p<0.05$ ); mean linear intercepts, $46.4 \pm 2.9$ versus $42.8 \pm 3.2$ versus $39.6 \pm$ 3.4 , control versus RGZ at $0.3 \mathrm{mg} / \mathrm{kg}$ or $3 \mathrm{mg} / \mathrm{kg}$, respectively, $* p<0.05)$ ]. Because enhanced alveolarization must be accompanied by increased vascularization, we next probed for the expression of VEGF and its receptor FLK-1 in RGZ-

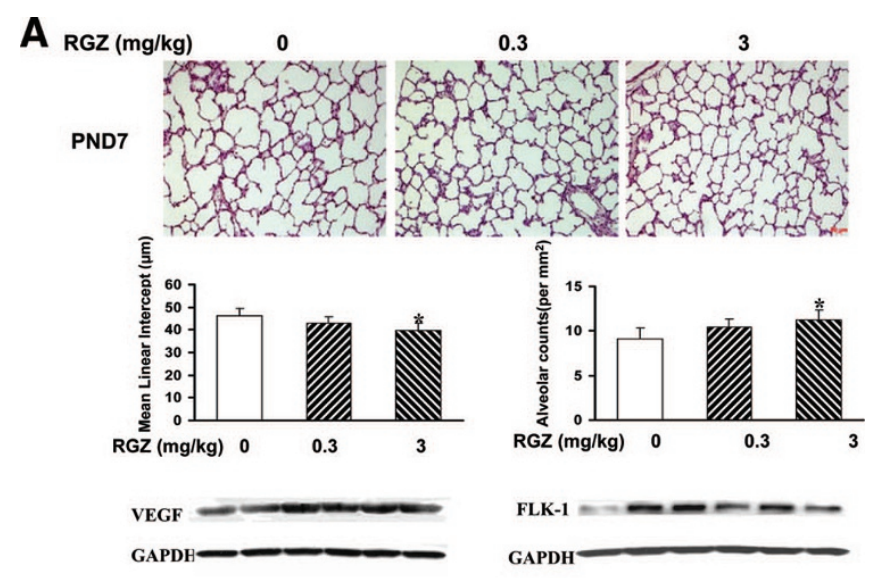

B
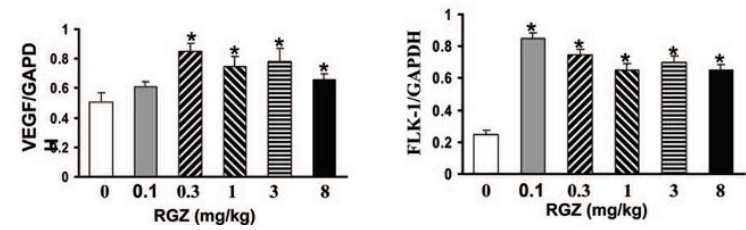

Figure 4. Effect of rosiglitazone on lung morphometry. The newborn rat pups were administered either diluent or RGZ in $100 \mu \mathrm{L}$ volume once daily intraperitoneally for $7 \mathrm{~d}$. RGZ treatment resulted in a significant increase in alveolarization in the RGZ $3 \mathrm{mg} / \mathrm{kg}$ treatment group, with a trend toward an increase in the RGZ $0.3 \mathrm{mg} / \mathrm{kg}$ treatment group [mean alveolar counts: control vs. RGZ, $0.3 \mathrm{mg} / \mathrm{kg}, 3 \mathrm{mg} / \mathrm{kg}, 9.1 \pm 1.2 v s .10 .4 \pm 1,11.3 \pm 1.1$, respectively, $* p<0.05$ ); mean linear intercepts: control vs. RGZ, $0.3 \mathrm{mg} / \mathrm{kg}, 3 \mathrm{mg} / \mathrm{kg}$, $46.4 \pm 2.9 v s .42 .8 \pm 3.2,39.6 \pm 3.4$, respectively, Fig. $4 A, n=6,{ }^{*} p<0.05$, RGZ vs. control)]. Representative $\mathrm{H} \& \mathrm{E}$ stained lung sections and the corresponding histograms are shown; Magnification $\times 10$. Furthermore, compared with controls, RGZ administration increased VEGF and FLK-1 expression significantly. Representative Western blots from the whole lung lysates and the corresponding density histograms are shown (Fig. 4B, $n=5$, mean \pm $\mathrm{SD},{ }^{*} p<0.05$, RGZ vs. control). 
treated animals. VEGF is a critical mediator of normal lung vascularization during development and is essential for the establishment of normal lung architecture (13). As predicted, with RGZ treatment, expression of both VEGF and FLK-1 increased significantly $(* p<0.05$, RGZ versus control; Fig. $4 B$ ).

Effect of RGZ on blood gas and serum electrolyte profile. There was no significant effect of RGZ on blood gas analyses ( $\mathrm{pH}, \mathrm{PaCO}_{2}$, and $\mathrm{PaO}_{2}$, Table 1) and serum electrolytes (serum potassium, sodium, and ionized calcium, Table 2) on either day 1 or day 7 at all doses of RGZ examined.

Effect of RGZ on blood glucose, cholesterol, triglyceride, and cardiac troponin levels. Because in the adult RGZ is used as a potent antidiabetic agent, we determined its effect on blood glucose levels (Table 3). There was no significant effect on blood glucose at either day 1 or day 7 , for all of the doses of RGZ examined except for the highest dose used, i.e., 8 $\mathrm{mg} / \mathrm{kg}$ for $7 \mathrm{~d}$, which resulted in statistically significantly lower glucose values compared with controls (84 \pm 15 versus $127 \pm 3$ (mean $\pm \mathrm{SD}),(* p<0.05, \mathrm{RGZ}$ versus control). Lastly, troponin I levels were undetectable in both-the $7 \mathrm{~d}$ control and RGZ treated groups.

Effect of RGZ on PPAR $\gamma$ and ADRP expression in peritoneal fat, liver, and kidney. Because the $\operatorname{PAAR} \gamma$ gene is expressed in a wide range of tissues, we next surveyed the effect of systemically administered RGZ on PPAR $\gamma$ and
ADRP expression in a few selected extra-pulmonary PPAR $\gamma$ expressing tissues such as the peritoneal fat (Fig. 5A), liver (Fig. 5B), and kidney (Fig. 5C). In general, $7 \mathrm{~d}$ systemic administration of RGZ increased PPAR $\gamma$ and ADRP expression in all extra-pulmonary PPAR $\gamma$-expressing tissues examined ( $* p<0.05$ versus controls; Fig. 5).

Effect of $P G_{J_{2}}$ on alveolar differentiation. To determine that the effects of the PPAR $\gamma$ agonist RGZ observed by us for neonatal rat lung maturation are not RGZ specific, in a series of experiments, we treated neonatal pups with another PPAR $\gamma$ agonist $\mathrm{PGJ}_{2}(0.1-1 \mathrm{mg} / \mathrm{kg})$ for $7 \mathrm{~d}$ and examined the expression of PPAR $\gamma$ and its down-stream target ADRP. Compared with controls, expression of both PPAR $\gamma$ and ADRP increased significantly with all three doses of $\mathrm{PGJ}_{2}$ examined $\left(* p<0.05, \mathrm{PGJ}_{2}\right.$ versus control; Fig. 6A). Similar to RGZs effects on functional markers of lung maturation, i.e., $\left[{ }^{3} \mathrm{H}\right]$ choline incorporation and $\left[{ }^{3} \mathrm{H}\right]$ triolein uptake, by the lung explants of treated animals, in general, $\left[{ }^{3} \mathrm{H}\right]$ choline incorporation and $\left[{ }^{3} \mathrm{H}\right]$ triolein uptake by the lungs of $\mathrm{PGJ}_{2}$-treated animals also significantly increased $(* p<$ $0.05, \mathrm{PGJ}_{2}$ versus control; Fig. $6 B$ ).

\section{DISCUSSION}

Because pulmonary immaturity is the principal contributor to the premature infant's significantly increased risk for mor-

Table 1. Blood gas measurements in day 1 and 7 of rosiglitazone treatment

\begin{tabular}{|c|c|c|c|c|c|c|}
\hline \multirow[b]{2}{*}{ Rosiglitazone (mg/kg) } & \multicolumn{2}{|c|}{$\mathrm{pH}$} & \multicolumn{2}{|c|}{$\mathrm{Pco}_{2}(\mathrm{~mm} \mathrm{Hg})$} & \multicolumn{2}{|c|}{$\mathrm{Po}_{2}(\mathrm{~mm} \mathrm{Hg})$} \\
\hline & Day 1 & Day 7 & Day 1 & Day 7 & Day 1 & Day 7 \\
\hline 0 & $7.40 \pm 0.02$ & $7.47 \pm 0.06$ & $44.8 \pm 9.36$ & $46.3 \pm 3.51$ & $38.8 \pm 8.3$ & $43.7 \pm 2.08$ \\
\hline 0.1 & $7.42 \pm 0.01$ & $7.43 \pm 0.04$ & $42.3 \pm 2.53$ & $45.0 \pm 9.85$ & $45.7 \pm 5.85$ & $32.0 \pm 3.61$ \\
\hline 0.3 & $7.41 \pm 0.04$ & $7.50 \pm 0.08$ & $45.8 \pm 6.03$ & $46.7 \pm 8.08$ & $43.0 \pm 5.13$ & $33.2 \pm 5.17$ \\
\hline 1 & $7.35 \pm 0.04$ & $7.48 \pm 0.07$ & $42.8 \pm 7.79$ & $45.7 \pm 2.89$ & $46.7 \pm 5.13$ & $29.3 \pm 2.22$ \\
\hline 3 & $7.40 \pm 0.02$ & $7.40 \pm 0.02$ & $54.3 \pm 3.05$ & $46.7 \pm 6.03$ & $44.3 \pm 3.78$ & $36.0 \pm 9.64$ \\
\hline 8 & $7.44 \pm 0.03$ & $7.45 \pm 0.04$ & $48.3 \pm 2.08$ & $47.0 \pm 5.57$ & $47.0 \pm 2.65$ & $30.0 \pm 2.0$ \\
\hline
\end{tabular}

Values are mean $\pm \mathrm{SD}, n=20$ pups.

Table 2. Blood electrolyte measurements in day 1 and 7 of rosiglitazone treatment

\begin{tabular}{|c|c|c|c|c|c|c|}
\hline \multirow[b]{2}{*}{ Rosiglitazone (mg/kg) } & \multicolumn{2}{|c|}{$\mathrm{K}^{+}(\mathrm{mEq} / \mathrm{L})$} & \multicolumn{2}{|c|}{$\mathrm{Na}^{+}(\mathrm{mEq} / \mathrm{L})$} & \multicolumn{2}{|c|}{$\mathrm{Ca}^{2+}(\mathrm{mEq} / \mathrm{L})$} \\
\hline & Day 1 & Day 7 & Day 1 & Day 7 & Day 1 & Day 7 \\
\hline 0 & $4.85 \pm 0.18$ & $4.85 \pm 0.69$ & $137.5 \pm 5$ & $127.3 \pm 2.3$ & $1.33 \pm 0.04$ & $1.49 \pm 0.06$ \\
\hline 0.1 & $5.18 \pm 0.09$ & $5.08 \pm 0.56$ & $132.3 \pm 1.2$ & $126.8 \pm 2.4$ & $1.38 \pm 0.02$ & $1.42 \pm 0.11$ \\
\hline 0.3 & $4.39 \pm 0.32$ & $4.97 \pm 0.77$ & $133.8 \pm 4$ & $125.8 \pm 2.4$ & $1.38 \pm 0.08$ & $1.46 \pm 0.07$ \\
\hline 1 & $4.83 \pm 0.63$ & $4.73 \pm 0.66$ & $133.5 \pm 3.3$ & $127.5 \pm 6.2$ & $1.40 \pm 0.09$ & $1.42 \pm 0.07$ \\
\hline 3 & $4.22 \pm 0.10$ & $4.53 \pm 0.49$ & $138.7 \pm 5.1$ & $128.8 \pm 1.9$ & $1.43 \pm 0.04$ & $1.47 \pm 0.12$ \\
\hline 8 & $4.99 \pm 1.11$ & $4.39 \pm 0.58$ & $137.7 \pm 3.1$ & $129.0 \pm 1.7$ & $1.33 \pm 0.05$ & $1.41 \pm 0.05$ \\
\hline
\end{tabular}

Values are mean $\pm \mathrm{SD}, n=20$ pups.

Table 3. Blood glucose and serum lipid measurements in day 1 day 7 of rosiglitazone treatment

\begin{tabular}{|c|c|c|c|c|c|c|}
\hline \multirow[b]{2}{*}{ Rosiglitazone (mg/kg) } & \multicolumn{2}{|c|}{ Glucose (mg\%) } & \multicolumn{2}{|c|}{ Cholesterol (mg/dL) } & \multicolumn{2}{|c|}{ Triglyceride (mg/dL) } \\
\hline & Day 1 & Day 7 & Day 1 & Day 7 & Day 1 & Day 7 \\
\hline 0 & $85.3 \pm 8.9$ & $126.7 \pm 2.9$ & $115.9 \pm 4.5$ & $147.0 \pm 20.5$ & $132.5 \pm 8.4$ & $134.9 \pm 5.8$ \\
\hline 0.1 & $91.8 \pm 5.1$ & $124.7 \pm 3.8$ & $106.5 \pm 10.9$ & $130.6 \pm 13.7$ & $118.7 \pm 9.2$ & $118.7 \pm 23.2$ \\
\hline 0.3 & $98.8 \pm 5.6$ & $128.0 \pm 5.3$ & $108.7 \pm 5.3$ & $143.6 \pm 22.7$ & $132.3 \pm 10.8$ & $113.1 \pm 8.9$ \\
\hline 1 & $87.2 \pm 8.6$ & $131.0 \pm 5.3$ & $105.5 \pm 3.2$ & $136.7 \pm 26.7$ & $130.1 \pm 7.5$ & $135.2 \pm 10.3$ \\
\hline 3 & $93.0 \pm 7.5$ & $136.3 \pm 11.7$ & $105.9 \pm 6.8$ & $142.9 \pm 7.33$ & $130.8 \pm 7.5$ & $111.8 \pm 7.0$ \\
\hline 8 & $83.0 \pm 4.6$ & $84.0 \pm 14.9$ & $105.9 \pm 9.7$ & $139.0 \pm 17.4$ & $131.3 \pm 9.5$ & $120.3 \pm 12.2$ \\
\hline
\end{tabular}

Values are mean $\pm \mathrm{SD}, n=20$ pups. 


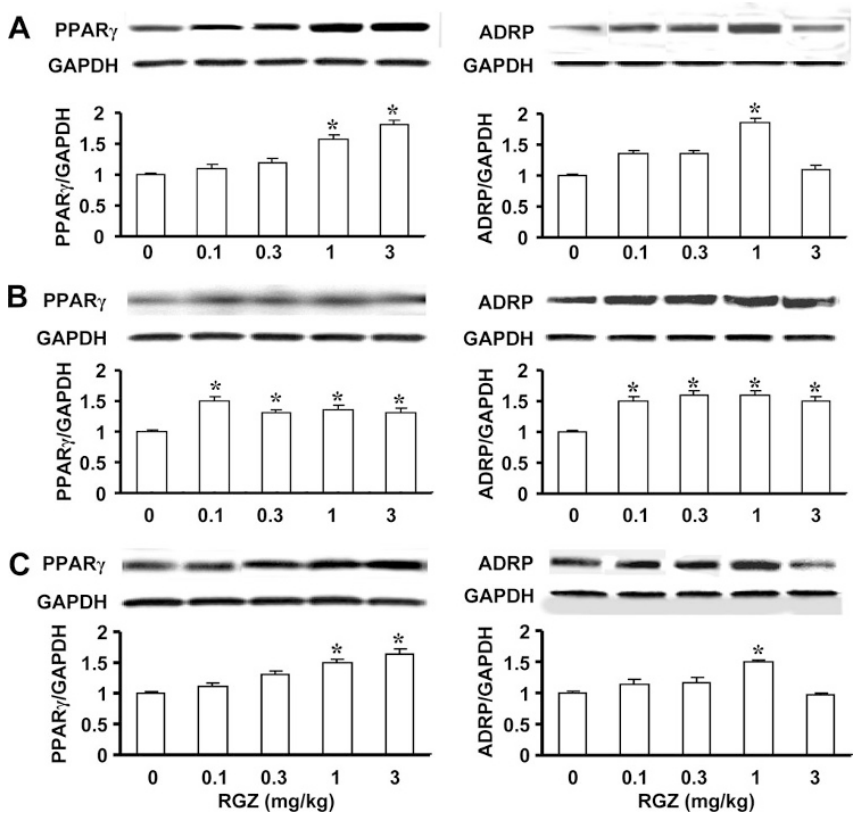

Figure 5. Effect of rosiglitazone on PPAR $\gamma$ and ADRP expression in peritoneal fat, liver, and kidney. The newborn rat pups were administered either diluent or RGZ in graded doses in $100 \mu \mathrm{L}$ volume once daily intraperitoneally for $7 \mathrm{~d}$, and then PPAR $\gamma$ and ADRP expression was examined in the whole tissue lysates of peritoneal fat $(A)$, liver $(B)$, and kidney $(C)$. In general, $7 \mathrm{~d}$ systemic administration of RGZ increased PPAR $\gamma$ and ADPR expression in all of the extra-pulmonary tissues examined. Representative Western blots from the whole tissue lysates and the corresponding density histograms are shown (Fig. 5, $n=5$, mean $\pm \mathrm{SD}, * p<0.05$, RGZ vs. control).
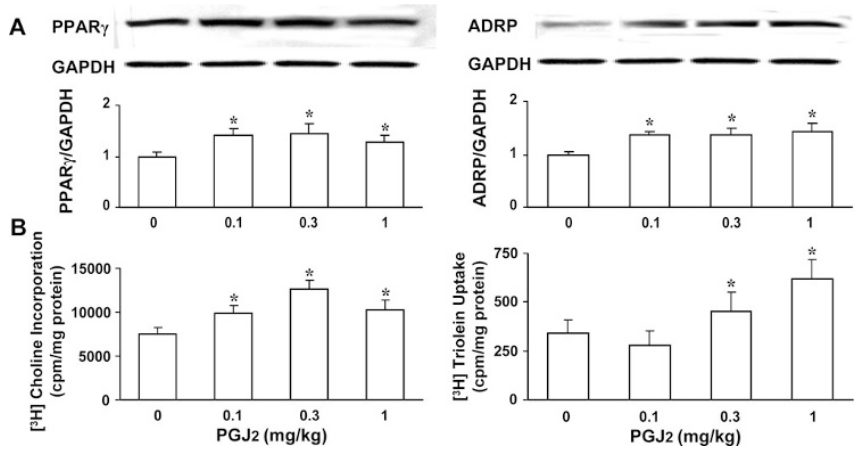

Figure 6. Effect of $\mathrm{PGJ}_{2}$ on alveolar differentiation. The newborn rat pups were administered either diluent or $\mathrm{PGJ}_{2}(0.1-1 \mathrm{mg} / \mathrm{kg})$ for $7 \mathrm{~d}$ and then PPAR $\gamma$ and ADRP expression were examined. Compared with controls, expression of both PPAR $\gamma$ and ADRP increased significantly with all three doses of $\mathrm{PGJ}_{2}$ examined $\left(* p<0.05, \mathrm{PGJ}_{2} v s\right.$. control; $A$. Similarly, $\left[{ }^{3} \mathrm{H}\right]$ choline incorporation and $\left[{ }^{3} \mathrm{H}\right]$ triolein uptake by the lungs of $\mathrm{PGJ}_{2-}$ treated animals also increased significantly (Fig. $6, n=6$, mean $\pm \mathrm{SD}, * p<0.05$, $\mathrm{PGJ}_{2}$ vs. control; $B$.

bidity and mortality, attempts to advance lung maturity have been a major research focus for decades. This has led to the widespread use of antenatal steroids, which result in significantly enhanced lung maturity, with the resultant significant decrease in morbidity and mortality associated with prematurity (5). However, in contrast to the beneficial effects of antenatal steroids, there is no intervention that has been shown to consistently enhance pulmonary maturity postnatally (1416). In fact, daily administration of dexamethasone to newborn rats from postnatal day 4 to 13 irreversibly impairs saccule septation (14), which persists at least until postnatal day 60 (15). Furthermore, significant concerns over the adverse effects of postnatal steroids on infants' neurodevelopment preclude their routine use during the postnatal period (16).

In this study, we show that the PPAR $\gamma$ agonist RGZ, given daily systemically to Sprague Dawley rat pups, results in significantly enhanced pulmonary maturity, as evidenced by increased expression of surfactant proteins $\mathrm{B}$ and $\mathrm{C}$, and increased surfactant phospholipids synthesis, the markers of pulmonary epithelial differentiation, at both days 1 and 7 . This was accompanied by the significantly increased expression of PTHrP receptor, PPAR $\gamma$, ADRP, and increased triolein uptake, key markers of lung mesenchymal differentiation, at both days 1 and 7. At day 7, there was evidence for increased alveolarization, as supported by increased radial alveolar count and decreased mean linear intercept, which was also accompanied by increased lung vascularization, as evidenced by increased expression of VEGF (and its receptor), the key regulator of lung vascularization during development. Furthermore, as expected, the effects of RGZ were not lung-specific because there was also increased expression of PPAR $\gamma$ and ADRP in all of the PPAR $\gamma$-expressing extra-pulmonary tissues examined. However, there were no significant effects of RGZ on blood gases, serum electrolytes, blood glucose, cholesterol, or triglyceride levels, except at the highest dose used, i.e., $8 \mathrm{mg} / \mathrm{kg}$, which resulted in statistically significantly lower blood glucose values, suggesting that systemically administered RGZ significantly enhanced lung maturation without significantly affecting basic blood biochemical and metabolic profiles. Based on these findings, we speculate that PPAR $\gamma$ agonists may be therapeutically effective agents for enhancing lung maturation and promoting lung injury repair in neonates.

In humans, PPAR $\gamma$ is highly expressed in adipose tissue, and serves as an important transcriptional regulator of genes involved in glucose and lipid metabolism, cell proliferation, and control of inflammation (17). Expression and activation of $\operatorname{PPAR} \gamma$ is sufficient to trigger the adipocyte differentiation cascade and to confer a lipid-storing phenotype on mesenchymal cells in culture (1). In the developing lung, PPAR $\gamma$ expression has been clearly documented in lipid-laden lung alveolar interstitial fibroblasts ( $\sim$ lipofibroblasts) and in alveolar type II (ATII) cells $(3,4,18)$. Although there are only limited data on PPAR $\gamma$ 's role in the alveolar epithelium, there is extensive information on its role in the lung mesenchyme $(2,4,19,20)$. Pulmonary lipofibroblasts express PPAR $\gamma$, as well as other genes involved in lipid metabolism, e.g., genes involved in the hydrolysis of triglycerides at the plasma membrane, in the transport of fatty acids across the plasma membrane, as well as ADRP, which is necessary for uptake, storage, and exocytosis of lipid droplets $(2,18)$. PPAR $\gamma$ expression in alveolar adepithelial lipofibroblasts has been shown to promote alveolar development and homeostasis via the PTHrP-PPAR $\gamma$ alveolar epithelial-mesenchymal paracrine signaling pathway $(2,18,19,21)$. PPAR $\gamma$ epithelial expression is also critical in lung development, as indicated by the fact that airway epithelial cell PPAR $\gamma$-deficient mice show persistent abnormalities in postnatal lung maturation, evidenced by 
enlarged airspaces and the accompanying alterations in lung physiology and whole lung extracellular matrix gene expression pattern (4). In addition to PPAR $\gamma$ 's previously highlighted role in lung alveolar epithelial-mesenchymal interactions, the data presented here for the first time also suggest its role in the pulmonary vasculature during lung development. This possibly provides an integrated mechanistic basis for enhanced lung development after exogenous systemic PPAR $\gamma$ agonist administration, i.e., coordinated stimulation of the epithelial, mesenchymal, and vascular compartments of the developing lung.

Although a variety of structurally distinct molecules have been shown to bind and activate $\operatorname{PPAR} \gamma$, due to extensive clinical experience with the synthetic thiazolidinedione compound RGZ, we chose to use RGZ in this study (20). The dose range of RGZ chosen in this study was based upon our previous work and that of others (22-25). The fact that lung maturation was stimulated by not only RGZ, but also by the naturally occurring PPAR $\gamma$ agonist $\mathrm{PGJ}_{2}$ suggests that this effect is not ligand-specific and is likely mediated by PPAR$\gamma$-dependent rather than PPAR-independent activities of PPAR agonists. Because activation of PPAR $\gamma$ also regulates the transcription of insulin-responsive genes involved in the control of glucose production, transport, and utilization, we also examined whether the use of RGZ would affect blood glucose in normal rat pups. It was reassuring to note that daily RGZ administration to neonatal pups for up to $7 \mathrm{~d}$ did not result in hypoglycemia. In addition, because PPAR $\gamma$ responsive genes also participate in the regulation of lipid metabolism, and have been shown to affect plasma lipid profiles when used long-term in adults (26), we examined the effect of RGZ administration for $7 \mathrm{~d}$ to neonatal rat pups on blood cholesterol and total triglyceride levels, but did not find any significant effect on these parameters. Furthermore, because RGZ has been shown to exacerbate and/or lead to cardiac failure (27), we examined its effect on plasma cardiac troponin levels and found undetectable troponin I levels in both control and $7 \mathrm{~d}$ RGZ-treated pups. Although it is reassuring to note that cardiac troponin I levels were below the detection limit of the kit we used, it cannot be concluded with certainty that RGZ administration did not affect cardiac troponin I levels at all. Lastly, it was also reassuring to note that systemic administration of RGZ for $7 \mathrm{~d}$ did not affect neonatal rat pup blood gases and serum electrolytes significantly.

It is important to note that as safety and efficacy of PPAR $\gamma$ agonists such as RGZ has not been tested in the neonatal/ pediatric population, their clinical use cannot be recommended at present. However, the work presented here provides proof-of-principle for their efficacy in promoting lung maturation. Furthermore, although it is reassuring to note that acute blood parameters examined here were not affected by up to $7 \mathrm{~d}$ of treatment with RGZ, more rigorous testing, including its long-term effects need to be evaluated before its use in the human infant can be considered. Overall, our data provide a strong case for further exploring the use of PPAR $\gamma$ agonists for the purposes of enhancing lung maturation and for possibly promoting lung injury/repair.

\section{REFERENCES}

1. Tontonoz P, Hu E, Spiegelman BM 1995 Regulation of adipocyte gene expression and differentiation by peroxisome proliferator activated receptor gamma. Curr Opin Genet Dev 5:571-576

2. Chen H, Jackson S, Doro M, McGowan S 1998 Perinatal expression of genes that may participate in lipid metabolism by lipid-laden lung fibroblasts. J Lipid Res 39:2483-2492

3. Torday JS, Torres E, Rehan VK 2003 The role of fibroblast transdifferentiation in lung epithelial cell proliferation, differentiation, and repair in vitro. Pediatr Pathol Mol Med 22:189-207

4. Simon DM, Arikan MC, Srisuma S, Bhattacharya S, Tsai LW, Ingenito EP, Gonzalez F, Shapiro SD, Mariani TJ 2006 Epithelial cell PPAR[gamma] contributes to normal lung maturation. FASEB J 20:1507-1509

5. 1995 Effect of corticosteroids for fetal maturation on perinatal outcomes. NIH Consensus Development Panel on the Effect of Corticosteroids for Fetal Maturation on Perinatal Outcomes. JAMA 273:413-418

6. Wapner RJ, Sorokin Y, Mele L, Johnson F, Dudley DJ, Spong CY, Peaceman AM, Leveno KJ, Malone F, Caritis SN, Mercer B, Harper M, Rouse DJ, Thorp JM, Ramin S, Carpenter MW, Gabbe SG; National Institute of Child Health and Human Development Maternal-Fetal Medicine Unite Network 2007 Long-term outcomes after repeat doses of antenatal corticosteroids. N Engl J Med 357:1190-1198

7. Ballard PL, Ballard RA, Granberg JP, Sniderman S, Gluckman PD, Kaplan SL, Grumbach MM 1980 Fetal sex and prenatal betamethasone therapy. J Pediatr 97:451-454

8. Nielson HC, Torday JS 2000 Sex differences in fetal lung development: Biology, Etiology, and Evolutionary Significance. In: Mendelson CR (ed) Endocrinology of the Lung-Development and Surfactant Synthesis. Totowa, New Jersey: Humana Press, pp 141-159

9. Willet KE, Jobe AH, Ikegami M, Newnham J, Sly PD 2000 Antenatal retinioic acid does not alter alveolization or postnatal lung function in preterm sheep. Eur Respir J 16:101-107

10. Srinivasan G, Bruce EN, Houtz PK, Bruce MC 2002 Dexamethasone-induced changes in lung function are not prevented by concomitant treatment with retinoic acid. Am J Physiol Lung Cell Mol Physiol 283:L275-L287

11. Rehan VK, Wang Y, Sugano S, Santos J, Patel S, Sakurai R, Boros LG, Lee WP, Torday JS 2007 In utero nicotine exposure alters fetal rat lung alveolar type II cell proliferation, differentiation, and metabolism. Am J Physiol Lung Cell Mol Physiol 292:L323-L333

12. Randell SH, Mercer RR, Young SL 1989 Postnatal growth of pulmonary acini and alveoli in normal and oxygen-exposed rats studied by serial section reconstructions. Am J Anat 186:55-68

13. Carmeliet P, Ferreira V, Breier G, Pollefeyt S, Kieckens L, Gertsenstein M, Fahrig M, Vandenhoeck A, Harpal K, Eberhardt C, Declercq C, Pawling J, Moons L, Collen D, Risau W, Nagy A 1996 Abnormal blood vessel development and lethality in embryos lacking a single VEGF allele. Nature 380:435-439

14. Massaro D, Massaro GD 1986 Dexamethasone accelerates postnatal alveolar wall thinning and alters wall composition. Am J Physiol 251:R218-R224

15. Massaro D, Teich N, Maxwell S, Massaro GD, Whitney P 1985 Postnatal development of alveoli. Regulation and evidence for a critical period in rats. J Clin Invest 76:1297-1305

16. Cerny L, Torday JS, Rehan VK 2008 Prevention and treatment of bronchopulmonary dysplasia: contemporary status and future outlook. Lung 186:75-89

17. Heikkinen S, Auwerx J, Argmann CA 2007 PPARgamma in human and mouse physiology. Biochim Biophys Acta 1771:999-1013

18. Rehan VK, Sugano S, Wang Y, Santos J, Romero S, Dasgupta C, Keane MP, Stahlman MT, Torday JS 2006 Evidence for the presence of lipofibroblasts in human lung. Exp Lung Res 32:379-393

19. Torday JS, Rehan VK 2007 Developmental cell/molecular biologic approach to the etiology and treatment of bronchopulmonary dysplasia. Pediatr Res 62:2-7

20. Standiford TJ, Keshamouni VG, Reddy RC 2005 Peroxisome proliferator-activated receptor-\{gamma $\}$ as a regulator of lung inflammation and repair. Proc Am Thorac Soc 2:226-231

21. Torday JS, Rehan VK 2002 Stretch-stimulated surfactant synthesis is coordinated by the paracrine actions of PTHrP and leptin. Am J Physiol Lung Cell Mol Physiol 283:L130-L135

22. Liu D, Zeng BX, Zhang SH, Yao SL 2005 Rosiglitazone, an agonist of peroxisome proliferator-activated receptor gamma, reduces pulmonary inflammatory response in a rat model of endotoxemia. Inflamm Res 54:464-470

23. Rehan VK, Wang Y, Patel S, Santos J, Torday JS 2006 Rosiglitazone, a peroxisome proliferator-activated receptor-gamma agonist, prevents hyperoxia-induced neonatal rat lung injury in vivo. Pediatr Pulmonol 41:558-569

24. Wayman NS, Hattori Y, McDonald MC, Mota-Filipe H, Cuzzocrea S, Pisano B, Chatterjee PK, Thiemermann C 2002 Ligands of the peroxisome proliferatoractivated receptors (PPAR-gamma and PPAR-alpha) reduce myocardial infarct size. FASEB J 16:1027-1040

25. Genovese T, Cuzzocrea S, Di Paola R, Mazzon E, Mastruzzo C, Catalano P, Sortino M, Crimi N, Caputi AP, Thiemermann C, Vancheri C 2005 Effect of rosiglitazone and 15-deoxy-Delta12,14-prostaglandin J2 on bleomycin-induced lung injury. Eur Respir J 25:225-234

26. Khan MA, St Peter JV, Xue JL 2002 A prospective, randomized comparison of the metabolic effects of pioglitazone or rosiglitazone in patients with type 2 diabetes who were previously treated with troglitazone. Diabetes Care 25:708-711

27. Home PD, Pocock SJ, Beck-Nielsen H, Gomis R, Hanefeld M, Jones NP, Komajda M, McMurray JJ 2007 Rosiglitazone evaluated for cardiovascular outcomes-an interim analysis. N Engl J Med 357:28-38 